\title{
(息)
}

Citation:

Folley, D and Thomson, S and Parker, S and Cope, N (2004) The Pipeline Project: A Holistic Approach to Teaching Multimedia. In: SIGGRAPH 2004, 08 August 2004 - 12 August 2004, Los Angeles, USA.

Link to Leeds Beckett Repository record:

https://eprints.leedsbeckett.ac.uk/id/eprint/3642/

Document Version:

Conference or Workshop Item (Published Version)

Copyright Restrictions Prevent ACM from Providing the Full Text for This Work

The aim of the Leeds Beckett Repository is to provide open access to our research, as required by funder policies and permitted by publishers and copyright law.

The Leeds Beckett repository holds a wide range of publications, each of which has been checked for copyright and the relevant embargo period has been applied by the Research Services team.

We operate on a standard take-down policy. If you are the author or publisher of an output and you would like it removed from the repository, please contact us and we will investigate on a case-by-case basis.

Each thesis in the repository has been cleared where necessary by the author for third party copyright. If you would like a thesis to be removed from the repository or believe there is an issue with copyright, please contact us on openaccess@leedsbeckett.ac.uk and we will investigate on a case-by-case basis. 


\section{The Pipeline Project: A Holistic Approach to Teaching Multimedia.}

\author{
Duncan Folley* \\ Leeds Metropolitan \\ University
}

\author{
Simon Thomson ${ }^{\dagger}$ \\ Leeds Metropolitan \\ University
}

\author{
Stephen Parker \\ Leeds Metropolitan \\ University
}

\author{
Dr Nick Cope- \\ Leeds Metropolitan \\ University
}

\begin{abstract}
An interesting educational development within the School of Technology at Leeds Metropolitan University (UK) has been the approach to the teaching of the level 2 BSc Multimedia Technology course. The level team has developed a structured, holistic approach to delivering modules. This has allowed students to develop skills and knowledge of the module subjects in semester one and then integrated the learning from ALL the modules in semester two. Working in groups they develop a major piece of work which has become known as "The Pipeline Project". This approach was further developed and enhanced as the level team went to the UK government-funded conference on group work and assessment (GWAP) at Bournemouth University.
\end{abstract}

The main area of development was the assessment process that allows for students to clearly see the aims and objectives of each module but within a more global project. Not only has this holistic approach benefited the students, it has also allowed staff to develop material that goes across modules and allows for team teaching and an integrated lecture programme. This logical approach to project work echoes the skills required in the multimedia industry. As part of the GWAP experience, the teams have now enhanced a peer assessment programme from which individual student attainment is obtained from group assessment.

Keywords: Integration, Assessment, Holistic Approach, Learning Teaching and Assessment, Group Work, Team Work, Peer Assessment.

\section{Introduction}

The multimedia industry has embraced the integration of computer software packages. They have realised that better integration and compatibility of software and hardware will produce better end results and will also improve workflow. In fact many of the major software developers are now introducing "suites" of products to purchase, further developing workflow efficiency between production stages and allowing for collaborative multi platform delivered products.

If the industry is doing this then surely educational establishments should follow suit and develop courses where differing but complementary subject areas (modules) are integrated.

Members of the academic community sometimes forget that it is Learning, Teaching and then Assessment. As educationists we are here to develop the student's interest and knowledge of a given subject or field of study. We facilitate the learning process to ensure that when our students leave University they can integrate successfully into a working environment. We must ensure that employability skills are developed and that they are those skills which the industry requires.
If our students are "unemployable" we must surely be seen as failing both the students and the industry for which they are developing. Therefore we must ensure learning, teaching and assessment reflects the real world approaches to work flow and product development. To do this, the general approach to assessment must change.

In a study in England presented by Professor Graham Gibbs at the GWAMP conference Bournemouth, one University was found to assess individual students over 130 times throughout their 3year degree program. It was found that you could remove over 125 of these assessments and, based on the grades for the remaining ones, the student would still end up with the same degree classification. We need to prepare our students for the 'real' world and the only way to do this is to develop assessments that are more closely linked to a real world environment.

\section{Exposition}

\section{Course Design}

At Leeds Metropolitan University the HND/BSc Multimedia Technology course has been designed to have the following course objectives:-

On completion of the programme the graduate will be able to:

-understand the context within which the media/multimedia industry operates;

-analyse and evaluate current developments in multimedia and Media related technologies and assess their impact upon the industry, products, production methods and markets;

- function in a range of roles/contexts within multimedia production including: Project planning and management, Audio production, Video production, Computer-based media production, Managing the creative process, Conceptual design and Technical product research/development;

-demonstrate the synergy which is required in the production of Multimedia products utilising multi-disciplined teams possessing a dynamic mix of creative/artistic and technical skills and abilities;

-produce a Multi-Media product to professional standard within a team working environment;

-demonstrate a range of acquired skills, knowledge allowing the expression of personal talents through a significant multimedia portfolio. 
To ensure that the course delivers all of these objectives the level 2 teaching team have designed the module structure of the course and also the assessment strategy to be the following: -

Student developers subject specific skills
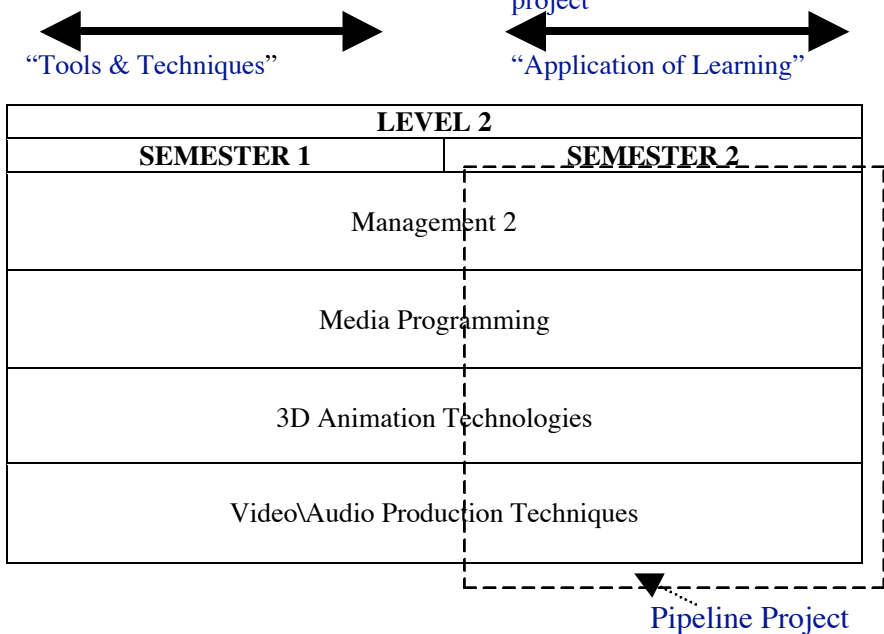

Figure 1

Course Structure for Level 2 HND / BSc Multi-Media Technology

Level 2 sees the student experience shift into the development phase in which the students will begin to acquire a range of creative, professional and technical skills. This development will be underpinned by theoretical studies integrated with practical application through module-based assessment and an integrative project, the Pipeline project.

We have developed the Pipeline project to complement the aims and objectives of the level and course. A major part of the Pipeline Project is the development of teamwork, as the course is designed to enhance group-working skills.

Teamwork is essential to the majority of multimedia productions today, productions are too big and require many skills for any one person to complete in a reasonable time scale, teamwork is cited as an essential requirement in many job adverts in the industry.

Yet many Universities shy away from assignments involving student group working because it is commonly perceived to be difficult to assess and even more problematic to extract an individual student's grade, which are required for academic awards. There are opposing theories about team learning, on the one hand teamwork is thought to be a good learning vehicle, students help each other, students can reflect on the experience and learn from their peers and, in a climate of larger class sizes and decreased individual contact with staff, students spend far more time with each other than with their tutors. Yet traditionally students 'working together' have been seen as cheating. Assignments are seen by most staff as 'individual work' and that by engaging students in group assessment you are encouraging plagiarism and cheating. The main problem voiced by staff is that group work is difficult to assess individuals within a group and the main problem voiced by students is that the assessment of group work is not fair. Both staff and students are concerned about free riders who do very little work by may benefit form sharing a group mark.

Staff are not always in a position to assess individual members' contribution to the team, only the students really know but staff generally feel students cannot assess properly. Assessment gives staff power over students and staff may feel a loss of this power in group work. We have tried to address this challenge by using assessment as yet another learning tool. Students need to learn and practice assessment as they may be required to use this skill as a manager in their career, students are asked to study team work theory, develop assessment criteria and assess the group including themselves.

The group work is very successful with students integrating their subjects and producing a far bigger professional piece of work than is possible in traditional single module or individual assessed work. As with much project work students drive themselves more than staff can ever do, in group work students motivate help each other and move learning onto a new level. Assessment Strategy

To develop a set of deliverables for each student within a group and allow varying marks across modules within the semester requires a clear assessment strategy. But not only that, its success is based on the commitment of the level team and the design structure of the assessment. The overall structure of the assessment took over 6 months to design, as each student should be able to get relevant marks across modules but also students should be able to get accurate individual grading from within a group environment.

In order to facilitate this, the "pipeline" structure includes:

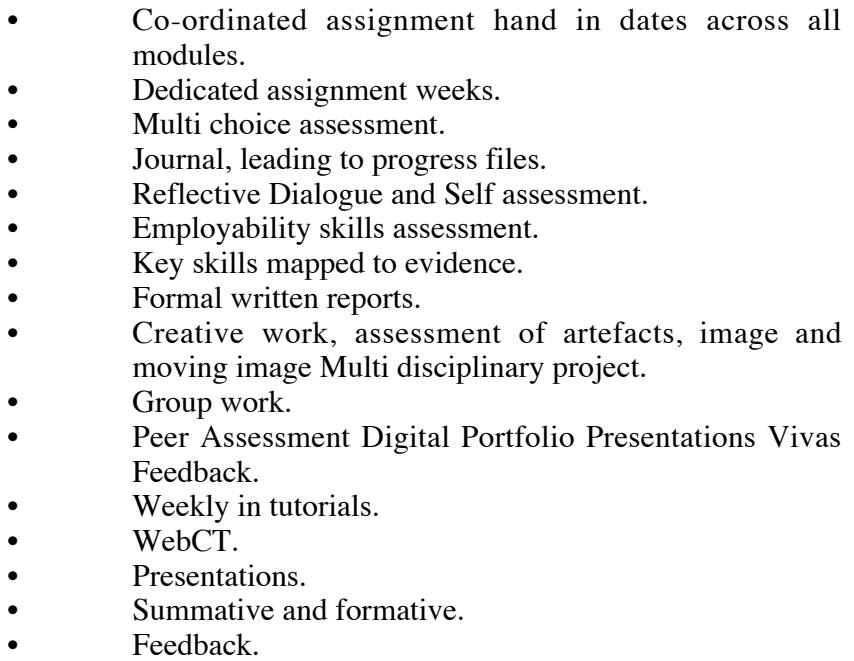

\section{Peer Assessment:}

The assessment of group work is in two stages.

1 Tutor marks the product of five students as a single piece of work.

2 Students are required to assess everyone in the group, including themselves three times in a semester. This peer assessment is moderated by staff and used as a weighting index to obtain an individual mark for the group product mark. 


\section{Assessment Process}

Semester 1 allows the students to develop their theoretical and technical knowledge within the modules which act as a strong foundation for the semester 2 Pipeline project.

The size and complexity of modern multimedia products normally requires people to work in a group to complete the work on time. In order to make small groups realistic of the Multimedia industry, students are asked to form a group normally of five students from within their tutorial group. The multimedia product they have to produce is an interactive story on $\mathrm{CD}$, in the following scenario:-

Each group is to consider themselves as a Product Research and Development team within NEWMEDIUM plc, a medium sized multimedia Production Company employing 100 people. NEWMEDIUM has been building a reputation within the industry for delivering cutting edge products using the latest technologies and the latest design ideas (it has recently won a European Union Industry award for innovation and technological leadership). The company is a subsidiary of VISUAL-PUBLISHING inc. this is a multinational company covering a wide range of media - printed publications (books and magazines), film, computer games, multimedia and the web.

VISUAL-PUBLISHING inc. has asked NEWMEDIUM plc to bid for a new project collaborating with one of its popular magazine publications. The Magazine is called ADVENTURE Zone a monthly publication featuring graphic novel style adventure stories. The magazine has established itself as a cult publication with a world-wide circulation. It is proposed that a CDROM/DVD-ROM will be included with the magazine, which will contain interactive adventure stories. The student group must produce a prototype interactive adventure to be presented to the parent company; this is a competitive situation as 5 other companies have been invited to bid. The company CEO is desperate to win the contract and wants each team to communicate the company values of innovation and inventiveness within NEWMEDIUM. The prototype product must be documented to the highest standards and if the bid is successful the product will be handed over to the production department as the successful team will be working on the next $R \& D$ project.

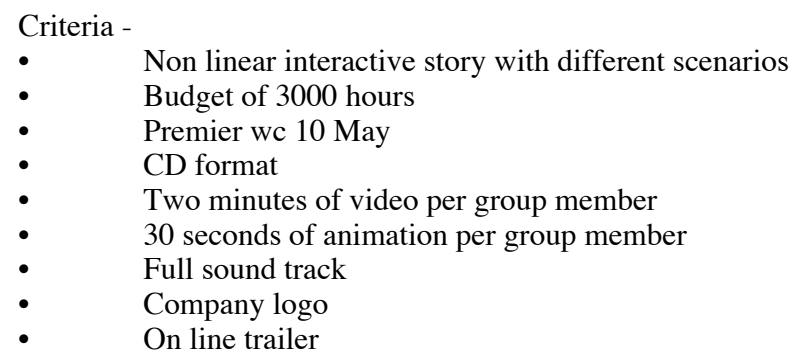

Before Christmas each student is expected to develop a possible storyboard in the Video/Audio Production Techniques module. Immediately after Christmas the group will select a storyboard for the group project, this is a decision made by the group based on the presentations they make to each other. Immediately after Intersemester week the group will then plan and cost the project to meet the learning outcomes of all semester two modules. The group must then manage the project and deliver to the specification on time and within budget. The assessment will be synoptic across all the modules and most of the assessment is for the group product weighted by peer assessment. Tutors set specific criteria for the assessment of the learning outcomes of each module, students submit a CD and other assessed work for each module, i.e. students will submit work for each module they are enrolled on.

\section{Conclusion}

The disadvantages perceived by some academic staff regarding group work are invariably based on misconceptions about peer assessment, a lack of understanding of just what benefits group work brings to the students learning, and also an unwillingness of the staff to allow students to break free from tradition assessment process (breaking the shackles of linear assessment) which tend to restrict creativity in order to ensure an easier time for assessment. When a high-flying student is placed within a group of students who are less capable than he/she is, there is a belief that he/she will be dragged down with the others. An alternative and more accurate scenario is the high-flyer has to raise his/her game even higher to explain complex theories to less able students. The less capable students receive peer learning and the all group develop as a coherent team learning from each other. At the end of the Pipeline project each student has gained from peer learning within a real world environment, where they will appreciate the problems of different departments within a multimedia company.

\section{References}

Professor Graham GIbBS -. The Open University. "Supporting Students Learning". In Proceedings of GWAMP 2003. Bournemouth University $12^{\text {th }}$ September 2003

"e-mail: d.folley@leedsmet.ac.uk †e-mail: s.thomson@leedsmet.ac.uk *e-mail: s.t.parker@leedsmet.ac.uk - e-mail: n.cope@leedsmet.ac.uk 